www.jmscr.igmpublication.org

Impact Factor (SJIF): 6.379

Index Copernicus Value: 71.58

ISSN (e)-2347-176x ISSN (p) 2455-0450

crossrefDOI: https://dx.doi.org/10.18535/jmscr/v6i6.187

Journal Of Medical Science And Clinical Research

\title{
Predictors of Need for Non-Invasive Mechanical Ventilation in Patients with Acute Exacerbation of Chronic Obstructive Pulmonary Disease
}

\author{
Authors \\ Elham Abdelhady Abdelghany ${ }^{1}$, Rasha Mohammed Emam ${ }^{1}$, Manar Samir Mohamed ${ }^{2}$ \\ ${ }^{1}$ Chest Department, Faculty of Medicine Minia University \\ ${ }^{2}$ Lecturer of Internal Medicine Deraya University
}

\begin{abstract}
Background: COPD remains a common cause of morbidity and mortality worldwide. NIV has been well established as the gold standard therapy for treatment of acute decompensated respiratory failure complicating an acute exacerbation of COPD (AECOPD) with reduced mortality and intubation rates compared to standard therapy. Objective: to evaluate the predictors for the need for NIV in management of AECOPD.

Methods: Eighty adult patients previously diagnosed as COPD presented with AECOPD were assessed with recording of demographic and clinical data, arterial blood gases (ABGs), $C$-reactive protein $(C R P)$, serum electrolytes (sodium (Na)\&potassium $(\mathrm{K})$ ) with previously performed spirometry.

Results: The current study showed higher smoking frequency and smoking index in group II patients that were treated with NIV, BMI mean \pm SD. was significantly higher in group I who were treated without need for NIV. Group II was presented by more frequent AECOPD, higher heart rate and respiratory rate and longer duration of hospital stay. More cases of group II showed positive CRP (60\%) versus $46.7 \%$ of group I cases, while mean \pm SD of CRP showed insignificant differences between both groups. Serum $N a$ and $K$ were significantly lower in group II. There was significant differences between both groups as regards $\mathrm{PH}$ and $\mathrm{PaO} 2 / \mathrm{FiO} 2$ as these values were significantly lower in group II patients. Univariate regression analysis elucidated that higher smoking index (SI), PaCO2, and frequent AECOPD were independent positive predictors of the need for NIV in treating cases of AECOPD and higher PaO2 and $\mathrm{PaO} 2 / \mathrm{FiO} 2$ were negative predictors of its requirement.

Conclusions: Higher smoking index and frequency, more frequent COPD exacerbations, higher heart rate and respiratory rate,lower serum electrolytes ( $\mathrm{Na} \& \mathrm{~K}$ ), lower $\mathrm{PH}$ and $\mathrm{PaO} 2 / \mathrm{FiO} 2$ can significantly indicate a more severe AECOPD and higher smoking index (SI), PaCO2, frequent AECOPD, or lower PaO2 and Pao2/FiO2 can be used as independent predictors for the need for NIV.

Keywords: COPD, AECOPD, NIV, ABGs, electrolytes, $\mathrm{Na}, \mathrm{K}$
\end{abstract}

\section{Introduction}

COPD remains a common cause of morbidity and mortality worldwide ${ }^{(1)}$. COPD exacerbations are defined as acute worsening of respiratory symptoms that result in additional therapy ${ }^{(2)}$.

Respiratory failure from airflow obstruction is a direct consequence of acute airway narrowing and critical increases in the airway resistance ${ }^{(3)}$. COPD
Patients with respiratory failure, whether acute or chronic have a worse prognosis than patients without respiratory failure. Non-invasive ventilation (NIV) has been proved to be a useful tool in both the acute hospital and chronic home care setting. NIV has been well established as the gold standard therapy for treatment of acute decompensated respiratory failure complicating an 
acute exacerbation of COPD (AECOPD) with reduced mortality and intubation rates compared to standard therapy ${ }^{(1)}$. The current study aimed to evaluate the predictors for the need for NIV in management of AECOPD to avoid delay in this decision with exposing the patient to complications of Invasive Mechanical Ventilation.

\section{Patients and Methods}

This is a prospective study. Eighty adult patients were included in this study recruited from inpatient chest department and respiratory intensive care unit of Minia University Hospital. All patients had a prior confirmed diagnosis of COPD on the basis of fixed airway obstruction on spirometry. All patients had post bronchodilator FEV1/FVC <0.70. Exacerbation of COPD was diagnosed on the basis of increase in dyspnea and other symptoms including sputum purulence and volume with increased couph and wheeze leading to change in medical therapy ${ }^{(4)}$.

Patients with underlying COPD admitted with another primary admitting diagnosis (e.g. Accidents, Stroke, Acute Myocardial Infarction) were excluded from the study. Also, patients with acute respiratory failure secondary to bronchial asthma, bronchiectasis, tuberculosis, pulmonary embolism, pulmonary edema, pneumothorax and myopathic/neurologic causes were also excluded.

Informed consent was obtained from the patient or the next of kin.

Clinical and demographic data were recorded at the time of admission, including age, sex, smoking data/status, BMI, frequency of AECOPD with recording of heart rate and respiratory rate and also complete general and local examinations were performed to all patients.

Respiratory failure was diagnosed by doing Arterial Blood Gases (ABGs) analysis which showed hypoxemia, hypercapnea or both and also showed the acid-base parameters.

Previously performed spirometry was obtained as baseline because all patients were too distressed to perform spirometry at time of examination. C reactive protein levels, serum electrolytes $(\mathrm{Na}$ and $\mathrm{K})$ were obtained from all patients.

Patients were managed by a team of physicians who decided the management strategy that was individualized for each patient according to the patient clinical status.

The study was approved by the local ethics committee

\section{Statistical Analysis}

Statistical analysis was performed using SPSS software version (20.0; SPSS Inc., Chicago). Results are expressed as the mean and standard deviation (SD) for continuous variables and as percentages for categorical variables. Differences in continuous variables were assessed by student's t-test and ANOVA. Chi-square test was used to determine the association between categorical variables. Correlation between PSQI scores and other variables were assessed by the Spearman rank correlation coefficient ( $r$ ). A P value of less than 0.05 was considered as statistically significant.

\section{Results}

Eighty adult patients were included in this study recruited from inpatient chest department and respiratory intensive care unit of Minia University Hospital; 55 (68.75\%) males and 25 (31.25\%) females, their ages ranged from 58 to 76 years old with a mean \pm standard deviation (SD)of 59.9 \pm 8.3 years. Patients were subdivided into 2 groups (Group I: 30 patients treated without need for NIV and Group II: 50 Patients treated with NIV)

Demographic and clinical data of both groups were shown in tables $1 \& 2$. Table 3 showed comparison between both groups regarding clinical and laboratory data. Significant statistical difference was observed between both groups regarding smoking, BMI, number of AECOPD per year, heart rate, respiratory rate and duration of hospital stay. 
Table (1) Demographic and clinical data among group I patients

\begin{tabular}{|c|c|}
\hline \multicolumn{1}{|c|}{ Variable } & $\begin{array}{c}\text { Frequency (Percentage \%) } \\
* \mathbf{M} \pm \text { SD. }\end{array}$ \\
\hline Age (years) & $* 60.5 \pm 6.6$ \\
\hline Gender: $\quad$ Males & $24(80 \%)$ \\
$-\quad$ Females & $6(20 \%)$ \\
\hline Smoking: $\quad$ Non-smoker & $14(46.7 \%)$ \\
$-\quad$ Smoker & $4(13.3 \%)$ \\
$-\quad$ Ex-smoker & $12(40 \%)$ \\
\hline SI $\quad$ * & $* 14.9 \pm 14.9$ \\
\hline Number of AECOPD per year & $10(33.3 \%)$ \\
$-\quad$ One & $6(20 \%)$ \\
- Two & $6(20 \%)$ \\
$-\quad$ Four & $8(26.7 \%)$ \\
\hline \hline Heart rate & $83.1 \pm 10.9$ \\
\hline Respiratory rate & $21.8 \pm 3.8$ \\
\hline \hline Duration of hospital stay (Days) & $* 9 \pm 2$ \\
\hline
\end{tabular}

$\mathrm{M} \pm$ SD. = mean \pm Standard deviation. SI: Smoking Index,

AECOPD: Acute Exacerbation of Chronic Obstructive Pulmonary Disease.

Table (2) Demographic and clinical data among group II patients

\begin{tabular}{|c|c|}
\hline Variable & $\begin{array}{c}\text { Frequency (Percentage \%) } \\
* \mathbf{M} \pm \text { SD. } \\
\end{array}$ \\
\hline Age (years) & $* 59.5 \pm 11.1$ \\
\hline $\begin{aligned} & \text { Gender: } \\
&- \text { Males } \\
&- \text { Females } \\
&\end{aligned}$ & $\begin{array}{l}31(62 \%) \\
19(38 \%)\end{array}$ \\
\hline $\begin{aligned} & \text { Smoking: } \\
&- \text { Non-smoker } \\
&- \text { Smoker } \\
&- \text { Ex-smoker }\end{aligned}$ & $\begin{array}{l}20(40 \%) \\
17(34 \%) \\
13(26 \%)\end{array}$ \\
\hline SI & $* 21.3 \pm 13.1$ \\
\hline $\begin{aligned} \text { Number of AECOPD per year } \\
-\quad \text { Zero } \\
-\quad \text { One } \\
-\quad \text { Two } \\
-\quad \text { Three } \\
-\quad \text { Four } \\
-\quad \text { Five } \\
-\quad \text { Six } \\
-\quad \text { Seven } \\
\end{aligned}$ & $\begin{array}{c}2(4 \%) \\
10(20 \%) \\
14(28 \%) \\
7(14 \%) \\
6(12 \%) \\
6(12 \%) \\
3(6 \%) \\
2(4 \%) \\
\end{array}$ \\
\hline Heart rate & $94.24 \pm 15.16$ \\
\hline Respiratory rate & $26.6 \pm 5.4$ \\
\hline Duration of hospital stay (Days) & *13.8土7.2 \\
\hline
\end{tabular}

$\mathrm{M} \pm \mathrm{SD}$. = mean \pm Standard deviation. SI: Smoking Index,

AECOPD: Acute Exacerbation of Chronic Obstructive Pulmonary Disease. 
Table (3) Comparison between Group I and group II regarding demographic and clinical data

\begin{tabular}{|c|c|c|c|}
\hline Variable & $\begin{array}{c}\text { Group I } \\
\mathbf{N}=30\end{array}$ & $\begin{array}{c}\text { Group II } \\
\mathrm{N}=50\end{array}$ & P-value \\
\hline Age: Range (Mean \pm SD). & $50-70(60.5 \pm 6.6)$ & $58-76(59.5 \pm 11.1)$ & 0.61 \\
\hline $\begin{array}{l}\text { Gender: Freq. }(\%) \\
\text { Male } \\
\text { Female }\end{array}$ & $\begin{array}{c}24(80 \%) \\
6(20 \%) \\
\end{array}$ & $\begin{array}{l}31(62 \%) \\
19(38 \%) \\
\end{array}$ & 0.08 \\
\hline $\begin{aligned} \text { Smoking: Freq. (\%) } \\
-\quad \text { Non-smoker } \\
-\quad \text { Smoker } \\
-\quad \text { Ex-smoker } \\
\end{aligned}$ & $\begin{array}{c}14(46.7 \%) \\
4(13.3 \%) \\
12(40 \%) \\
\end{array}$ & $\begin{array}{l}20(40 \%) \\
17(34 \%) \\
13(26 \%) \\
\end{array}$ & $0.05^{*}$ \\
\hline SI (Mean \pm SD). & $14.9 \pm 14.9$ & $21.3 \pm 13.1$ & $0.05^{*}$ \\
\hline BMI (Mean \pm SD). & $28.7 \pm 7.1$ & $23.9 \pm 5.2$ & $0.001 *$ \\
\hline $\begin{aligned} & \text { Number of AECOPD per year } \\
&- \text { Zero } \\
&- \text { One } \\
&- \text { Two } \\
&- \text { Three } \\
&- \text { Four } \\
&- \text { Five } \\
&- \text { Six } \\
&- \text { Seven } \\
&\end{aligned}$ & $\begin{array}{c}10(33.3 \%) \\
6(20 \%) \\
6(20 \%) \\
8(26.7 \%)\end{array}$ & $\begin{array}{c}2(4 \%) \\
10(20 \%) \\
14(28 \%) \\
7(14 \%) \\
6(12 \%) \\
6(12 \%) \\
3(6 \%) \\
2(4 \%)\end{array}$ & $0.024 *$ \\
\hline Heart rate & $83.1 \pm 10.9$ & $94.24 \pm 15.16$ & $0.000 *$ \\
\hline Respiratory rate & $21.8 \pm 3.8$ & $26.6 \pm 5.4$ & $0.000^{*}$ \\
\hline Days of hospital stay (Mean \pm SD). & $9 \pm 2$ & $13.8 \pm 7.2$ & $0.000^{*}$ \\
\hline
\end{tabular}

$\mathrm{N}=$ number of cases, Freq. $=$ Frequency, $\mathrm{M} \pm \mathrm{SD}=$ Mean \pm Standard deviation, *significant $(\mathrm{P}$ value $<0.05)$.

SI: Smoking Index. BMI: Body Mass Index.

Comparing laboratory parameters of the 2 groups (Table 4) elucidated significant statistical difference between both groups regarding presence of positive CRP with more cases of group II showing positive CRP (60\%) versus $46.7 \%$ of group I cases, with statistically insignificant difference regarding its $\mathrm{M} \pm \mathrm{sd}$. There was significantly lower serum $\mathrm{K}$ in group II patients $(3.2 \pm 0.45)$ versus $(3.4 \pm 0.41)$ in group I patients (p0.007), together with lower serum $\mathrm{Na}$ in group II patients $(132.04 \pm 3.7)$ than group I patients (134.53 \pm 3.29$)(\mathrm{p} 0.003)$.

Table (4) Comparison between Group I and group II Laboratory data

\begin{tabular}{|c|c|c|c|}
\hline Variable & $\begin{array}{c}\text { Group I } \\
\mathbf{N}=\mathbf{3 0} \\
\text { Freq. }(\%)\end{array}$ & $\begin{array}{c}\text { Group II } \\
\quad \mathrm{N}=\mathbf{5 0} \\
\text { Freq. }(\%)\end{array}$ & P-value \\
\hline $\begin{array}{l}\text { CRP +ve } \\
\text { CRP-ve }\end{array}$ & $\begin{array}{l}14(46.7 \%) \\
16(53.3 \%)\end{array}$ & $\begin{array}{l}30(60 \%) \\
20(40 \%)\end{array}$ & $0.04 *$ \\
\hline Variable & $\mathbf{M} \pm \mathbf{S D}$ & $\mathbf{M} \pm$ SD & \\
\hline CRP (mg/L) & $1.3 \pm 0.6$ & $1.5 \pm 0.5$ & 0.11 \\
\hline $\mathrm{Na}(\mathrm{mmol} / \mathrm{l})$ & $134.53 \pm 3.29$ & $132.04 \pm 3.7$ & $0.003^{*}$ \\
\hline $\mathrm{K}(\mathrm{mmol} / \mathrm{l})$ & $3.4 \pm 0.41$ & $3.2 \pm 0.45$ & $0.007 *$ \\
\hline
\end{tabular}

$\mathrm{N}=$ number of cases, Freq. = Frequency, $\mathrm{M} \pm \mathrm{SD}=$ Mean \pm Standard deviation, *significant $(\mathrm{P}$ value $<0.05)$.

CRP:C-Reactive Protein.+ve: Positive. - ve: Negative. Na: Sodium. K: Potassium. Mmol/l: millimol per litre.

Table 5 showed differences between both groups regarding $\mathrm{ABGs}$ and spirometric measurement parameters. It elucidated that there was significant differences between both groups as regards $\mathrm{PH}$ and $\mathrm{PaO} 2 / \mathrm{FiO} 2$ as these values were significantly lower in group II patients. 
Table (5) Comparison between Group I and group II regarding Pulmonary Function Tests (Arterial Blood Gases and Spirometry parameters)

\begin{tabular}{|c||c|c|c||}
\hline \hline Variable & $\begin{array}{c}\text { Group I } \\
\mathbf{N}=30 \\
\text { Mean } \pm \text { SD }\end{array}$ & $\begin{array}{c}\text { Group II } \\
\text { N=50 } \\
\text { Mean } \pm \text { SD }\end{array}$ & P-value \\
\hline \hline$-\mathbf{P H}$ & $7.35 \pm 0.02$ & $7.32 \pm 0.57$ & $0.002^{*}$ \\
\hline \hline$-\mathbf{P a O}_{2}$ & $48.3 \pm 9.3$ & $47.08 \pm 11.7$ & 0.6 \\
\hline \hline$-\mathbf{P a C O}_{2}$ & $58.1 \pm 5.3$ & $62.8 \pm 16.6$ & 0.13 \\
\hline \hline$-\mathbf{P a O}_{\mathbf{3}} / \mathbf{F i O}_{2}$ & $29.9 \pm 1.9$ & $29.3 \pm 6.8$ & 0.6 \\
\hline \hline- FEV1 & 228.943 .7 & $190.9 \pm 37.7$ & $0.000^{*}$ \\
\hline \hline
\end{tabular}

$\mathrm{N}=$ number of cases, $\mathrm{M} \pm \mathrm{SD}=$ Mean \pm Standard deviation, * *ignificant $(\mathrm{P}$ value $<0.05)$. $\mathrm{PaO}_{2}$ : Arterial blood oxygen tension. $\mathrm{PaCO}_{2}$ : Arterial blood carbon dioxide tension. $\mathrm{HCO}_{3}$ : Sodium bicarbonate. $\mathrm{PaO}_{2} / \mathrm{FiO}_{2}$ : Arterial blood oxygen tension/Fraction of inspired oxygen. FEV1: Forced Expiratory Volume in $1^{\text {st }}$ second. FVC: Forced Vital Capacity.

As shown in table 6, high $\mathrm{PaCO} 2$ and SI and more frequent AECOPD increase the possibility of need for NIV in management of patients with
AECOPD. On the other hand, higher $\mathrm{PaO} 2$ and higher $\mathrm{PaO} 2 / \mathrm{FiO} 2$ decreases it.

Table (6) Univariate Cox Regression for predictors for need for NIV

\begin{tabular}{||l||c||c||c||}
\hline & B & P-value & OR \\
\hline \hline PaO2 & -0.468 & $0.006^{*}$ & 1.597 \\
\hline \hline PaCO2 & 0.280 & $0.004^{*}$ & 1.323 \\
\hline \hline PaO2/FiO2 & -0.046 & $0.001^{*}$ & 0.879 \\
\hline \hline SI & 0.046 & $0.011^{*}$ & 0.222 \\
\hline \hline AECOPD & 1.525 & $0.008^{*}$ & 4.597 \\
\hline
\end{tabular}

$\mathrm{PaO}$ 2: Arterial blood oxygen tension. PaCO2: Arterial blood carbon dioxide tension. PaO2/FiO2: Arterial blood oxygen tension/Fraction of inspired oxygen. SI: Smoking Index. AECOPD: Acute Exacerbation of COPD. OR: Odd ratio, CI: Confidence interval *significant $(\mathrm{P}$ value $<0.05)$

\section{Discussion}

Comparing the demographic data of both groups, group II patients showed an older age but to a non-significant value ( $p$ 0.61). This is in concordance with Schiavo et al., $2016^{(5)}$ as they found that patients group who required NIV was insignificantly older than the other group (p 0.94). This agrees with Ramesh et al., 2016(3) as they found that the ventilated group has an older age $(70.18 \pm 12.31)$ versus $(61 \pm 8.90)$ in the nonventilated group.

Insignificant difference was found between both groups regarding gender predilection with more

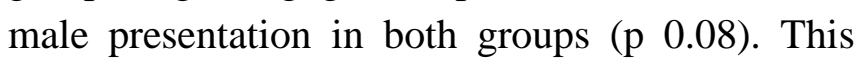
agrees with Schiavo et al., $2016^{(5)}$ as they also found insignificant difference between both groups regarding gender.

The present study revealed statistically higher smoking frequency and smoking index in group II whose exacerbations were more severe and required NIV ( $\mathrm{p}$ 0.05). Moreover, univariate regression analysis elucidated that higher SI is an independent predictor for the need for NIV. This agrees with Franciosi et al., $2006^{(6)}$ as they proved in their meta-analysis that the number of smoking related pack-years increased with the severity of exacerbation and their results showed a clear difference between in- and out- patients settings regarding smoking.

The current study revealed that group II patients had lower BMI $(23.9 \pm 5.2)$ than group I patients (28.7 \pm 7.1$) \quad$ with a statistically significant difference ( $\mathrm{p}$ 0.001). This agrees with the results of Vitacca et al., $1996^{(7)}$ as they found lower ideal body weight (IBW) \% in the group needed MV. Laaban et al., $1993^{(8)}$ found that malnutrition was more frequent and more severe in AECOPD patients requiring MV. Poor nutritional status can adversely affect pulmonary function through impairment of respiratory muscle strength and 
exercise tolerance and moreover, through decreasing ventilatory drive and altering lung defense mechanisms ${ }^{(9)}$

Cao et al., 2010(10)found that higher mortality was associated with underweight individuals and they also found that BMI associated with lower risk of mortality was $25 \mathrm{~kg} / \mathrm{m} 2$ or more. Also they stated that low BMI is frequent in patients hospitalized due to AECOPD and higher BMI was independently predictive of better long-term survival. The current results also agrees with Franciosi et al., 2006 ${ }^{(6)}$ as they found in their meta-analysis that BMI was statistically different between the out-patient setting and the in-patient setting.

The present study showed a significant statistical difference between both groups regarding frequency of AECOPD per year (p 0.024) with more frequent exacerbation in group II patients and that the increased frequency of AECOPD per year is an independent predictor for the need for NIV. Near to these results, Miravitlles et al., $2011^{(11)}$ found more frequent exacerbation in patients in need for invasive MV $(2.6 \pm 1.7)$ than those not requiring it $(2.5 \pm 2)$ but to an insignificant degree. This may be explained that they studied frequency of exacerbations in the last year only.

The current study revealed a statistically significant difference between both groups regarding heart rate which was higher in the ventilated group $(94.24 \pm 15.16)$ versus $(83.1 \pm 10.9)$ beats per minute in the non-ventilated group $(\mathrm{p}$ 0.000). This is in accordance with Schiavo et al., $2016^{(5)}$ who found significantly higher HR in the NIV group $(\mathrm{p}<0.001)$. This also agrees with Franciosi et al., 2006 ${ }^{(6)}$ as they found little variation in heart rate between levels of exacerbations with clear differences in heart rate between in- and out- patients and they explained that it may be due to the associated anxiety and dyspnea due to the exacerbation or may be due to an underlying cardiovascular disease that is more prominent in the severe COPD patients. Moreover, respiratory rate was also significantly higher in the ventilated group than the nonventilated group (26.6 \pm 5.4 and $21.8 \pm 3.8$ breaths per minute respectively) (p 0.000). Gravil et al., $1998^{(12)}$ stated that respiratory rate of $>25$ breaths per minute and heart rate of 110 beats per minute or more were arbitrary cut off points indicating a severe exacerbation.

Length of hospital stay (LOS) was significantly longer in group II patients (p 0.000). This agrees with the study of Wang et al., 2014(13) who proved that higher arterial $\mathrm{PaCO} 2$ was associated with a prolonged LOS. This also agrees with Chandra et al., 2007 (14)who reported that duration of hospital stay was longer for patients who needed ICU care.

A significant statistical difference was observed between both groups regarding CRP with more cases in group II showed positive CRP than group I (p 0.04) and mean \pm SD. of CRP was higher in group II patients but to a non-significant level (p 0.11). This agrees with Milacic et al., $2016^{(15)}$ who found that the higher the CRP level, the higher was the COPD severity and that the level of CRP was higher in patients with a high modified medical research council (mMRC) scale and a high COPD Assesment Test (CAT) score. Moreover, Cano et al., 2004 ${ }^{(16)}$ proved that plasma CRP was a major determinant of hospitalization and death risks in patients with end-stage respiratory diseases.

The current study compared both groups regarding $\mathrm{Na}$ and $\mathrm{K}$ levels. The study showed a significantly lower Naand K levels in group II patients and both groups had lower than normal values. This can be attributed to the more use of Beta- 2 agonists in the more severe cases, as these medications cause electrolytes disturbances ${ }^{(17)}$. Moreover, Goli et al., $2016^{(18)}$ found significantly lower PH in patients with electrolyte disturbance which is also present in the current study. They also found a significantly low level of serum sodium $(132 \pm 5.65 \mathrm{Meq} / \mathrm{lit})$ and potassium $(3.29 \pm 0.96$ $\mathrm{Meq} / \mathrm{lit})$ ) in subjects with acute exacerbation of COPD than their healthy controls $(\mathrm{Na}+=140 \pm 2.28$ Meq/lit and $\mathrm{K}+=4.51 \pm 0.02 \mathrm{Meq} / \mathrm{lit}(\mathrm{p}<0.05)$. 
These results also agree with Chandra et al., $2007^{(14)}$ as they found that levels of $\mathrm{Na}$ and $\mathrm{K}$ were lower in the non-survivor group of patients than the survivor group admitted with AECOPD.

Regarding ABGs analysis, the study elucidated higher $\mathrm{PaCO} 2$ and $\mathrm{HCO} 3$ with lower $\mathrm{PH}, \mathrm{PaO} 2$ and $\mathrm{PaO} 2 / \mathrm{FiO} 2$ in group II patients with significant difference only regarding $\mathrm{PH}$ values.

Significant statistical difference was observed between both groups regarding $\mathrm{PH}$ value which was lower in group II with mean \pm sd of (7.32 \pm 0.57$)$ versus $(7.35 \pm 0.02)$ in group I (p 0.002). This is near the results of Ramesh et al., $2016^{(3)}$ who found these values to be $7.30 \pm 0.08$ in the ventilated group versus $7.37 \pm 0.08$ in the nonventilated group. Franciosi et al., 2006 ${ }^{(6)}$ also found a statistically significant difference between exacerbation levels II and III with respect to $\mathrm{PH}$ $(\mathrm{p}=0.003)$.

Regarding PaCO2 level, the present study revealed higher level in group II patients than group I patient $(62.8 \pm 16.6$ versus $58.1 \pm 5.3)$ to an insignificant level ( $p$ 0.13) and univariate regression analysis proved that $\mathrm{PaCO} 2$ was an independent predictor for need for NIV as higher $\mathrm{PaCO} 2$ level increase the possibility of need for NIV by 1.323 times $(\mathrm{p}=0.004)$. Ramesh et al., $2016^{(3)}$ agree with this as they found that one of the main predictors of mechanical ventilation was the first day $\mathrm{PaCO} 2$. Shah et al., 2018 ${ }^{(1)}$ also stated that persistent acidosis $(\mathrm{pH}<7.35)$ and hypercapnia $\left(\mathrm{PaCO}_{2}>6.5 \mathrm{kPa}\right)$ is one of the established criteria for AECOPD patient selection for NIV.

Bicarbonate level (HCO3) was higher in group II patients and this agrees with Franciosi et al., $2006^{(6)}$ who found that bicarbonate level increased in exacerbation from level II to level III.

Regarding oxygenation level, $\mathrm{PaO} 2$ and $\mathrm{PaO} 2 / \mathrm{FiO} 2$ were lower in group II patients $(\mathrm{p}=$ 0.13 and 0.000 respectively) and univariate regression analysis showed that higher $\mathrm{PaO} 2$ decreased liability for NIV requirement by 1.597 times $(\mathrm{p}=0.006)$ and higher $\mathrm{PaO} 2 / \mathrm{FiO} 2$ decreased it by 0.879 times $(p=0.001)$. This is in concordance with Franciosi et al., 2006 ${ }^{(6)}$ as they elucidated that oxygen saturation was gradually decreased with increasing exacerbation severity and it also decreased in in-patient than out-patient setting.

Pulmonary spirometry showed lower levels of FEV1 and FVC in group II than group I with insignificant statistical difference (p <0.05). Franciosi et al., 2006 ${ }^{(6)}$ also reported that FEV1 and FVC decreased from exacerbation level I to level II. Moreover, Vitacca et al., $1996^{(7)}$ proved that FVC (\% predicted) provided a significant distinction between the 2 studied groups (Those requiring $\mathrm{MV}$ and those not requiring it).

\section{Conclusion}

Higher smoking index and frequency, more frequent COPD exacerbations, higher heart rate and respiratory rate, lower $\mathrm{PH}$ and $\mathrm{PaO} 2 / \mathrm{FiO} 2$ can significantly indicate a more severe AECOPD and higher smoking index (SI), $\mathrm{PaCO} 2$, frequent AECOPD, or lower $\mathrm{PaO} 2$ and $\mathrm{Pao} 2 / \mathrm{FiO} 2$ can be used as independent predictors for the need for NIV.

\section{Recommendations}

We recommend the design of more longitudinal studies or meta-analysis with the use of more advanced techniques and assessment of more markers like other electrolytes or trace elements abnormalities that may affect the severity of exacerbation together with the involvement of higher number of patients.

\section{Limitations}

Small number of patients is a major limitation in the current study

\section{References}

1. Shah NM., D'Cruz RF., Murphy PB. (2018).Update: non-invasive ventilation in chronic obstructive pulmonary disease. J Thorac Dis.; 10(1): S71-S79.

2. Global Initiative for Chronic Obstructive Lung Disease. Global Strategy for the 
Diagnosis, Management and prevention of Chronic Obstructive Pulmonary Disease. Management of exacerbation. Pp 99. Barcelona, Spain:GOLD; 2018.

3. Ramesh M., Banala R., Kumar K. (2016). Predictors for mechanical ventilation in acute exacerbation of COPD with respiratory failure. International Journal of General Medicine and Pharmacy (IJGMP); 5(5):15-20.

4. AnthonisenNR.,Manfreda J., Warren CP., Hershfield ES., Harding GK., Nelson NA. (1987). Antibiotic therapy in exacrebations of chronic obstructive pulmonary disease. Ann Intern Med; 106(2): 196-204.

5. Schiavo A., Renis M., Polverino M., Lanuzzi A., Polverino F. (2016). Acid-base balance, serum electrolytes and need for non-invasive ventilation in patients with hypercapnic acute exacerbation of chronic obstructive pulmonary disease admitted to an internal medicine ward. Multidisciplinary Respiratory Medicine; 11:23

6. Franciosi LG., Page CP., Celli BR., Cazzola M., Walker MJ.,Danhof M., Robe KF., Pasqua OE. (2006). Markers of exacerbation severity in chronic obstructive pulmonary disease. Respiratory Research; 7(1):74.

7. Vitacca M., Clini E., Porta R., Foglio K., Ambrosino N. (1996). Acute exacerbations in patients with COPD: predictors of need for mechanical ventilation. EurRespir J; 9(7):1487-93.

8. Laaban JP., Kouchakji B., Dore MF., Orvoen-Frija E., David P., Rochemaure J. (1993). Nutritional status of patients with COPD and acute respiratory failure. Chest; 103(5):1362-68.

9. Rochester DF., Esau SA. (1984). Malnutrition and respiratory system. Chest; 85(3):411-15.

10. Cao C., Wang R., Wang J., Bunjhoo H., Xu Y., Xiong W. (2010). Body Mass Index and Mortality in Chronic Obstructive Pulmonary
Disease: A Meta-Analysis.

PLOS ONE;7(8):e43892.

11. Miravitlles M., Izquierdo I., Herrejon A., Torres JV., Baro E., Borja J., On behalf of the ESFERA investigators (2011). COPD severity score as a predictor of failure in exacerbations of COPD. The ESFERA study. Respiratory Medicine; 105(5):740-47.

12. Gravil JH., Al-Rawas OA., Cotton MM., Flanigan U., Irwin A., Stevenson RD. (1998). Home treatment of exacerbations of chronic obstructive pulmonary disease by an acute respiratory assessment service. Lancet; 351(9119):1853-55.

13. Wang Y., Stavem K., Dahl FA., Humerfelt S., Haugen T. (2014). Factors associated with a prolonged length of stay after acute exacerbation of chronic obstructive pulmonary disease (AECOPD). International Journal of chronic obstructive pulmonary disease; 9:99-105.

14. Chandra D., Guntupalli K., Guleria R. (2007). Hypotension is a predictor of mortality in acute exacerbation of chronic obstructive pulmonary disease. Indian J Chest Dis Allied Sci 49:13-18.

15. Milacic N., Milacic B., Milojkovic M., Ljubisavljevic S., Vodopic S., Hasanbegovic M., Durovic M. (2016). Correlation of C-Reactive Protein and COPD Severity. ActaClin Croat;55:41-48.

16. Cano NJ., Pichard C., Eng HR., CourtFortune I., Cynober L., Gerard-Boncompain M., Cuvelier A., Laaban J., Melchior J., Raphael J., Pison CM., The Clinical Research Group of the Societe Francophone de Nutrition Enterale et Parenterale (2004).C-Reactive Protein and Body Mass Index Predict Outcome in End-Stage Respiratory Failure. Chest; 126(2):540-46.

17. Yang CT., Lin HC., Lin MC., Wang CH., Lee CH., Kuo HP. (1996). Effect of beta 2adrenoceptor agonists on plasma potassium and cardiopulmonary responses on exercise in patients with chronic obstructive 
pulmonary disease. Eur J ClinPharmacol.; 49(5):476-82.

18. Goli G., Mukka R., Sairi S. (2016). Study of serum electrolytes in acute exacerbation of chronic obstructive pulmonary disease patients. Int J Res Med Sci. ;4(8):3324-27.

\begin{abstract}
Abbreviations
COPD: Chronic Obstructive Pulmonary Disease. NIV: Non-Invasive Ventilation. AECOPD: Acute Exacerbation of Chronic Obstructive Pulmonary Disease. $\mathrm{M} \pm \mathrm{SD}$ : Mean \pm Standard deviation. SI: Smoking Index. $\mathrm{N}=$ number of cases. Freq. = Frequency. BMI: Body Mass Index. CRP: C reactive protein. Na: Sodium. $\mathrm{K}$ : Potassium.ABGs: Arterial Blood Gases. PaO2: Arterial blood oxygen tension. PaCO2: Arterial blood carbon dioxide tension. HCO3: Sodium bicarbonate. $\mathrm{PaO} 2 / \mathrm{FiO} 2$ : Arterial blood oxygen tension/Fraction of inspired oxygen. FEV1: Forced Expiratory Volume in 1st second. FVC: Forced Vital Capacity. OR: Odd ratio. CI: Confidence interval. LOS: Length Of hospital Stay.
\end{abstract}

